\title{
IAWS representation at the Chinese Academy of Forestry: 50th anniversary celebrations
}

\author{
John Barnett
}

During 27-28 October 2008, the Chinese Academy of Forestry sponsored an international symposium, at which invited heads of research organizations provided presentations on "Forest Research in Response to Global Change". The IAWS official invitees were President Frank Beall and Past President Xavier Deglise. President Beall gave a presentation on "Contributions of IAWS Fellows to Climate Change Information", which was the invited topic. Among the delegates were nine IAWS Fellows (Bao, Beall, Chen, Deglise, Hse, Jiang, Saddler, Shimizu, Zhang), and representatives of four of the IAWS Supporting Members, including CAF. A special lunch was hosted by Fellow Jiang to honour IAWS Fellows and other friends from her years as President of CAF. In addition, Director Kelin Ye sponsored a visit to the Research Institute of Wood Industry for a small group of Canadian visitors and IAWS Fellows, and held a banquet afterwards. In addition to the IAWS delegation, there were representatives of the following organizations: IUFRO, United Nations Convention to Combat Desertification (UNCCD), ITTO, FAO, International Popular Commission (IPC), International Network for Bamboo and Rattan (INBAR), Asia Pacific Association of Forestry Research Organizations (APAFRI), World Forest Center (WFC), and World Wide Fund for Nature (WWF, China).

John Barnett

Past President of IAWS 